\title{
Papel del Anestesiólogo en el tratamiento del gran quemado
}

La literatura suele afirmar, con razón, que los grandes quemados son uno de los pacientes más complejos que un equipo médico puede enfrentar. El tratamiento de grandes quemados es un trabajo de equipo en el que necesariamente están incorporados los anestesiólogos. Se suele decir también que la anestesia del quemado grave es única por la diversidad de situaciones que se presentan.

La pregunta es: ¿Cuáles son esas situaciones?

En los pacientes, tales situaciones están determinadas por los cambios fisiopatológicos que desencadenan las quemaduras extensas y que comprometen todos los órganos y sistemas, los que condicionan, entre otros, cambios en la farmacodinamia que influyen en el manejo anestesiológico.

Todo quemado con un compromiso mayor del $20 \%$ de la superficie corporal o incluso menor en los extremos de la vida, sufre un impacto sistémico de envergadura proporcional a la magnitud de la lesión. Magnifica el impacto el deterioro natural de las capacidades de autodefensa y autorregulación producto de la edad, comorbilidades y lesiones concomitantes.

A eso sumemos que estas alteraciones fisiopatológicas son cambiantes a lo largo de la evolución como resultado de la interacción entre el curso natural de la enfermedad y las acciones terapéuticas clínicas, quirúrgicas y anestesiológicas.

El desarrollo del conocimiento, en lo que a grandes quemados se refiere, dio un salto cualitativo cuando Zora Janzekovic, en 1970, propuso escarectomizar precozmente. La adopción en 1980 de este procedimiento como gold standard para el manejo de quemaduras de espesor total, produjo una mejoría sustantiva de la sobrevida e impulsó la necesidad de crear unidades especializadas que se hicieran cargo de estos tratamientos en las condiciones de lo que hoy llamamos Unidades de Paciente Crítico.

La mejoría de la sobrevida permitió el rescate de pacientes más graves y complejos, lo que a su vez impulsó la investigación y el desarrollo del conocimiento más allá del tratamiento quirúrgi- co al conjunto del manejo médico, de enfermería y rehabilitación.

Sin embargo, ese progreso no tuvo el correspondiente correlato en el Sistema Público de Salud de nuestro país. Las estadísticas del Hospital de Urgencia Asistencia Pública (HUAP) nos muestran que los resultados se mantuvieron sin variaciones significativas hasta el año 2004.

Hasta entonces la mortalidad de pacientes críticos se mantuvo por sobre el $70 \%$. Atribuimos esa situación al uso, hasta entonces, del Índice de Gravedad como Predictor de Sobrevida. La intervención del año 2005 produjo un descenso a la mitad en ese año. Posteriormente ha continuado descendiendo aunque, como es esperable, a un ritmo menor.

Esa observación pone de manifiesto que no sólo se trata de información y conocimiento. Existen otras condicionantes de los resultados determinadas por el contexto, el perfil de los pacientes, los recursos humanos y materiales, el soporte físico y equipamiento. No obstante, en los tres primeros años (2005-2007), los recursos materiales se mantuvieron constantes. Es claro que más allá de los recursos materiales y la planta física lo determinante es el desarrollo de un equipo cuya actividad no sólo se coordine mejor, se sume, sino que se potencie.

Ordenamos esa actividad como una secuencia de procesos en los que el resultado de uno es el soporte del siguiente, planificados estratégicamente buscando oportunidad en la indicación, eficacia en la ejecución, evaluando resultados prospectivamente para hacer rectificaciones oportunas.

Estos pacientes no se resuelven en un solo tiempo quirúrgico. Requieren de varias intervenciones planificadas estratégicamente evaluando la relación costo beneficio, ya que si bien cada una de ellas tiene un objetivo terapéutico, implican una agresión a un organismo ya agredido.

En las condiciones actuales se ha superado el antiguo paradigma que esperaba estabilizar el pa- 
ciente antes de iniciar el tratamiento quirúrgico. De hecho la anestesia puede ser parte de la reanimación. En ese contexto, el anestesiólogo debe lidiar con un paciente con severos trastornos hemodinámicos como resultado de alteración de la permeabilidad, potencial depresión miocárdica y aumento de la resistencia periférica por liberación de vasoactivos. Alto riesgo de falla pulmonar debido a las alteraciones de permeabilidad, insuficiente $o$ excesivo aporte de volumen en la reanimación o peor aún, compromiso por injuria inhalatoria.

La extensión de las heridas y/o la localización de zonas donantes en un paciente potencialmente inmunodeprimido, generan un alto riesgo de infección por contaminación al inicio de la evolución y en etapas posteriores de diseminación. Por lo mismo, se hacen necesarias medidas de aislamiento protector que agregan complejidad a la anestesia. Se dificulta la instalación de sensores de monitoreo, obliga a seleccionar alternativas y localizaciones específicas para cada caso.

La alta frecuencia de compromiso de cara y cuello a la que se puede sumar injuria inhalatoria, eleva la dificultad de manejo de la vía aérea. Más complejo aún si la localización de la quemadura o la ubicación de las zonas donantes exigen colocar el paciente en prono en la mesa de operaciones.

El incremento de la frecuencia de obesidad mórbida también se ve reflejado en los pacientes grandes quemados y por cierto implican un desafío adicional anestesiológico y quirúrgico.

Alto riego de hipotermia debido a destrucción de la circulación dérmica responsable de la termorregulación, a lo que se suma la falla hemodinámica, lo que convierte a las zonas con compromiso profundo en una coraza fría e inerte que debe ser eliminada con la escarectomía.

La escarectomía agrega un riesgo adicional: hemorragia. Riesgo que se incrementa en la fase inicial por destrucción de plaquetas y en etapas posteriores por coagulopatía producida por la combinación de varios factores: el síndrome de respuesta inflamatoria sistémica (SRIS), la falla de órganos y la infección. Consecuentemente aparecen los riesgos de politransfusión.

La mejor manera de prevenir este riego es anticipar la escarectomía lo más precozmente posible antes que se desencadene el SRIS.

El Protocolo de Tratamiento Integrado Clínico-Quirúrgico, desarrollado en el HUAP, tiene la particularidad de tomar los conceptos actuales del tratamiento de grandes quemados y aplicarlos, optimizando el uso de recursos, potenciando las capacidades del equipo, a las condiciones del Sistema Público de Salud. El eje principal es la precisión en el diagnóstico y la formulación de un pronóstico en función del cual se define y planifica cada intervención, sus resultados se evalúan, prospectivamente. El análisis sistemático de la experiencia se incorpora como nuevo conocimiento.

Se indica escarectomía precoz y cobertura inmediata para las lesiones de espesor total. Auto, homo o heteroinjerto, dependiendo de la extensión y disponibilidad en las lesiones escarectomizadas. Protección de las células epiteliales viables en las lesiones de espesor parcial. Se utiliza láminas microporosas como apósito primario en las mismas. Intervenimos los pacientes en quirófano cada cuatro días.

Este mismo modelo ha sido replicado en nuestra otra Unidad en Clínica Indisa con resultados similares. En ambos casos el conjunto del equipo se fue desarrollando en la práctica cotidiana. En el caso del HUAP los anestesiólogos estaban familiarizados con pacientes quemados, aunque no con este modelo de atención y la complejidad de los nuevos sobrevivientes. En el caso de INDISA esa experiencia no existía lo que implica que si bien "no es lo mismo conocer cuál es el camino, que haberlo recorrido" una adecuada gestión clínica permite la rápida incorporación de nuevos profesionales en esta tarea.

Uno de los aspectos que parece necesario optimizar es la superación del quiebre que supone en algunas ocasiones la transferencia del paciente de su unidad de intensivo al pabellón de operaciones. Hay equipos y Servicios que han buscado superar ese quiebre logrando que el mismo profesional sea residente de intensivo y anestesiólogo. Pareciera este un aspecto necesario de probar y evaluar para saber si efectivamente hace diferencias significativas. Por ahora parece valioso compartir el conocimiento y la experiencia de manera de abrir nuevos espacios al tratamiento de grandes quemados.

Dr. Jorge Villegas C. Jefe de Servicio de Quemados HUAP (2004-2014). Jefe de Equipo de Quemados INDISA. 